УДК 821

\title{
А.С. Якунин
}

\section{ПРИЁМ СТИЛИЗАЦИИ ДИНШЕНХАС В ПЬЕСЕ М. КАРР «МЭЙ»}

В статье рассматривается характерный для современной ирландской драматургии приём диншенхас и его стилизация, с помощью которой драматург преображает объекты художественного пространства и наделяет персонажей ментальными образами. Анализируется воплощение диншенхас в пьесе «Мэй», а также оценивается его роль в раскрытии мифологического потенциала творчества Марины Карр.

Ключевые слова: ирландская драма, диншенхас, стилизация, ментальный образ, художественное пространство.

DOI: $10.35634 / 2412-9534-2019-29-3-524-528$

Ирландская драма всегда стояла особняком от западноевропейской. Имена У.Б. Йейтса, Дж. Синга, Ш. О’Кейси, О. Уайлда, Б. Шоу составляют целый период, названный Ирландским литературным возрождениием. Острыми темами на Изумрудном острове по-прежнему оставались взаимоотношения государства и церкви, задававшие направления культурного развития и патриотического здоровья нации. Со второй половины XX в. драматургия стала «главным выразителем ирландской независимости в период политических волнений, порожденных мировым кризисом, религиозным упадком и остросоциальными коллизиями» [11. Р. 1].

Творчество ирландских драматургов последней четверти XX в., «зависшее» на гребне экономической карусели 1990-х гг., критики иронически окрестили театром кельтского тигра (Celtic Tiger theatre). Политическая обстановка уже потеряла отклик в сознании народа, поскольку былое противостояние националистических группировок сошло на нет, а религиозные предрассудки, занимавшие умы ирландцев в начале XX в., отошли на второй план, уступив место проблемам этнических меньшинств и гендерного неравноправия.

Персонажи этого периода в истории Ирландии - прекариат (социально неустроенные люди, находящаяся не столько за гранью прожиточного минимума, сколько в ситуации полной утраты своей независимости). Поднимаются такие темы, как утрата символической связи с корнями (фетишизация М. Макдонаха), женское противостояние патриархальному обществу (феминистское письмо М. Карр), значение исторической справедливости для индивидуума (принцип контингентности С. Барри).

Исследование ирландской драматургии в контексте географической соотносимости содержит в себе такое понятие как диншенхас. В научном обиходе оно появилось в труде С.В. Шкунаева «Предания и мифы средневековой Ирландии» как вариант перевода сложного слова диншенхас - «др.-ирл. dinn / dind 'холм, дворец, (замечательное) место' и seanchas 'старина', 'предание'» - «старина мест» [4. С. 275]. Изначально диншенхас представляет собой тексты, описывающие происхождение примечательных мест Ирландии, исследователи относят их к XI-XII вв.

Ирландский поэт Нюала Ни Дональ (Nuala Ni Dhomhnaill) отмечает тот факт, что традиция диншенхас началась с прибытия в Ирландию в железном веке кельтов, чьи мифы и культура происходили из таинственных священных мест обитания континентальных племён. «Христианизация и письменность добавили ещё один слой к уже сильно закодированной матрице» [7. Р. 429], в которой смешение языческих и христианских коннотаций географических названий позволяло «сосуществовать прошлому и критике настоящего» [7. Р. 429]. «Старина мест», почерпнутая из письменных источников ирландских монахов-переписчиков, сохраняет в себе черты присущие устной традиции именно они легли в основу современных переложений локальных легенд. Эти легенды бытовали как в поэтической, так и в прозаической форме. Первая, наиболее древняя, содержалась в ирландских сагах в виде экфразиса [7. Р. 419-421]; вторая акцентировала внимание на повествовании, которое зачастую строилось на этимологии «старины мест». Данный подход, при котором история подстраивалась под субъективную интерпретацию наименования места, оказывался недостоверным и вёл к тому, что исконное древнеирландское значение утрачивалось и подменялось новым толкованием.

Между терминами «диншенхас» и «хронотоп» следует отметить концептуальные различия, несмотря на общую установку места: если в хронотопе она значится в неразрывном сочетании с временем протекания события, то в диншенхас - с особым состоянием субъекта, в котором запечатлевается некий ментальный образ [7. Р. 421-422]. Последний, справедливо отмечает Ж.П. Сартр, «нацелен на 
какую-то реальную вещь сквозь призму психического содержания» [3. С. 123]. Кроме того, понятие хронотопа включает в себя все виды сопряженности пространства и времени, которые могут не связываться с ирландской «стариной мест». При очевидных аналогиях можно отметить производные отношения между трактовками терминов, поскольку пространственно-временная структура повествований, подобных диншенхас, подлежит описанию посредством категории хронотопа.

Однако имеет место и сходство терминов, по которому «старину мест» и хронотопы объединяет категория антропоцентричности. Последние, по мнению М.М. Бахтина, отмеченные «существенной взаимосвязью пространственных и временных отношений» [1. С. 341], дополнялись и самой ролью человека в окружающем его мире: «Человек объединяет “ценностный мир объектов” в пространстве и времени. Природа - предмет его активного воздействия, остальные объекты - продукты его деятельности, его труда, его творческой активности» [1. С. 289]. Диншенхас также включает в себя этот «ценностно-иерархический» компонент, который организует единство художественного текста и вместе с тем придаёт ему исторический колорит.

Например, в Новое время процесс ассимиляции ирландцев англичанами сопутствовал актуализации «старины мест», что позднее обнаружилось в самосознании ирландских писателей XX в. Одним из тех, кто воспринял традицию, усвоенную из наложения культурных парадигм, был Брайан Фрил (Brian Friel, 1923-2015), автор пьесы «Нужен перевод» (1980). В ней драматург ставит ключевой вопрос, находящийся в центре многих литературно-философских интерпретаций феномена «старины мест»: о значении памяти, запечатленной в названиях локаций, связанной с судьбами давно ушедших людей. Он изображает Ирландию 1833-го г., самобытную и идиллическую, в которую вторгся английский отряд, прибывший составлять топографическую карту местности. Миссия персонажей - капитана Лэнсея и лейтенанта Йолланда - состояла в том, чтобы перевести без потерь ирландские топонимы. Фрил близко подошёл к проблематике диншенхас, вложив в уста одного из героев мысль о том, что название, как и сам человек, обладает личной памятью имени:

«Оуэн: Мы называем этот перекресток Тобаир Врее. А почему мы зовем его Тобаир Врее? Я тебе отвечу. Тобаир означает колодец. А Врее? Это искаженное от имени Бриан (Произносит погэльски.). Бриан... Вот все, что с годами осталось от Тобаир Бхриаин. Так вот. Сто пятьдесят лет тому назад там был колодец. И заметь, стоял он не на перекрестке дорог. В этом-то и штука. Стоял он 8 поле, неподалеку от перекрестка. Жил там старик по имени Бриан. Лицо у него было обезображено растительностью. И пришло ему в голову, что вода в этом колодце святая. Стал он приходить туда каждый день и умываться ею. А растительность все не исчезала. Однажды утром Бриана нашли утонувшим в этом колодце. С тех пор этот перекресток и называется Тобаир Врее, хотя колодец уже давно высох». [пер. М. Стронина] [3. С. 221] (здесь и далее курсив мой. - А.Я.).

В размышлениях персонажа содержится интерпретация драматургом прозаической формы диншенхас, на передний план которого выступает образ колодия. И только затем он обретает человеческую легенду с помощью различных доводов Оуэна - биологического («давно нет в живых»), документального («ничего не осталось») и ментального («никто не помнит в приходе»). В то же время философский вопрос героя о том, что делать с названием колодца, наводит на мысль о двоякой интерпретации места, которое само по себе исторично. Достопримечательность вблизи перекрёстка это уже миф, то самое «нечто», по воспоминанию американского писателя Торнтона Уайлдера, «постоянно удерживаемое перед внутренним взором» в тот момент, когда «пьеса становится пейзажем» (цит. по: [8. Р. 93]). В современной пьесе «Нужен перевод» впервые обозначен фактор возникновения «старины места»: отчуждение ирландцев от родного языка и утрата ими совокупности знаний о конкретном физическом объекте.

Другим важным материалом о диншенхас в ирландской литературе конца ХХ в. является лекция 1977 г., прочитанная поэтом и общественным деятелем Шеймасом Хини в Музее Ольстера [9]. Она заключает в себе такое понятие как «чувство места» (статья, опубликованная под одноимённым заглавием - "The Sense of Place". - A.Я.), которое вытекает из понимания человеком места, где он живет, из признания длящегося влияния истории места на современность и приверженности индивида к части сообщества мыслителей-единомышленников - граждан «страны восприятия» (“country of the mind”).

Данная концепция «чувства места», использованная ещё У.Б. Йейтсом, в конце 1970-х гг. была переработана поэтом Хини и в последние десятилетия XX в. звучала со сцены как дань памяти традициям ирландского театра. Сосредоточенность Хини на теме ирландских болот - кладези ирландских истории, мифов, артефактов и останков пришельцев из прошлого - позволила автору глубже изучить «чувство места», а также проследить версии диншенхас у современных ирландских писателей. 
В творчестве Марины Карр (род. 1960) сосредоточением «старины места» становится Мидленд - центральный регион Ирландии, внутри которого прошли детство и молодость драматурга. Объединение трёх анализируемых пьес в трилогию носит неофициальный характер, поскольку в каждом произведении преобладают отличные друг от друга местный колорит, свои сюжетный и композиционный планы. Марина Карр отдает предпочтение природе как ментальному конструкту, а не статичному пейзажу: «Природа, облеченная в человеческую память или человеческую ассоциацию, является той природой, которая очаровывает меня. <..> Природа, появление которой ничем не мотивировано в пьесе, меня не интересует, но природа, которая вкладывает в память или характер персонажа ассоциацию или веру, делается особо значимой. Это другое измерение» [10. Р. 154].

Героини Марины Карр - это обладательницы волевых черт, сопротивляющиеся национальной репрезентации женщин в счастливом браке, пытающиеся освободиться от стереотипа МатериИрландии. Персонажи драматурга - тонкие и чувственные ирландки, отгородившие себя от мирской суеты несчастливым замужеством. Пьеса-воспоминание «Мэй» (“Тhe Мai”, 1994) представляет 40-летнюю героиню и её мужа, в отношениях которых возникла прохлада, психологически интерпретированная их повзрослевшей дочерью. В пьесе изображены четыре поколения семьи главной героини, что демонстрирует богатую палитру родственных связей. Карр неслучайно рисует портрет семейного древа - в большинстве пьес драматурга изображается трагедия рода, одно из поколений которого обречено на страдания.

Композиционно “Тhe Маi” делится на две части: первый акт начинается летним днём 1979 г., когда супруг героини, Роберт, возвращается домой после пятилетнего отсутствия. Действие пьесы на протяжении полутора лет - с лета 1979 г. до Рождества 1980 г. - сосредотачивается на женской вере в чудо и желании сокровенного. Особенностью сюжетного развития пьесы является отсутствие событий, протекающих в реальном времени: в сюжет вносятся коррективы нарратором - Милли, дочерью Мэй. В примечании к пьесе указано, что она "remains onstage throughout the play" (в течение действия пребывает на сцене. - А.Я.), где её задача представить следующие планы повествования: комментирование как способ введения дескриптивного уровня, авторепрезентация как смешение художественного и публицистического уровней и сказание как смешение художественного и мифологического уровней. Фабула пьесы, таким образом, реконструируется только из нарратива Милли, который располагается фрагментами по всему тексту.

Комментируя, Милли занимает отстраненную позицию, тем самым пытаясь объективно передать воспоминания о себе в шестнадцатилетнем возрасте, когда произошло самоубийство матери; столетняя прабабка Фриклан и тётка Бек приезжают погостить в дом на Совином озере - в дом, который построила Мэй. Обе родственницы делают вид, что не замечают, как Мэй переживает одиночество - они сосредоточены на собственных неудачах: «...родилась и выросла на Инис Фриклан, к северу от озера Бофин. Своим появлением она обязана мимолетной встрече одной незамужней островитянки и марокканского или испанского моряка (никто точно и не помнит), от которого не было ни слуху ни духу после зачатия <..> Неважно, кем он был, но от него прабабке Фриклан передались тёмная кожа и страсть ко всему недосягаемому и экзотическому [5. Р. 115-116] (здесь и далее перевод мой. - А.Я.).

Описанием дома становится семейный портрет: гости Мэй - носители карикатурных черт, приобретенных извне: «Обе тётки Мэй, столпь коннемарской округи, решили не брать с собой брошюры о разводе для отдыхающего семейства. Вместо этого они как-то заявились чудесным осенним днём вооружённые молитвами, наплечниками и листовками об ужасах добрачного соития, которые они распространяли среди нас, детей, с шуршащими двадцатифунтовыми банкнотами» [5. Р. 135]. Поведение родственников (по этому поводу в словах Милли сквозит ирония) уже давно стало притчей во языцех, в том числе и для главной героини.

Авторепрезантация представлена переживаниями и чувством обиды Милли-подростка по поводу ухода отца: дочь в косвенной речи называет его только Роберт. Она помнит, как мать послала её, одиннадцатилетнюю, в лавку мясника, как объяснила происходящее за иголкой и ниткой - той символической скрепой, которая помогла бы ей сплотить семью. Отчаяние Милли возникло в тот момент, когда она поняла, что матери ничем нельзя помочь. Уже будучи девушкой, накануне похорон матери, Милли решает наладить связь с отцом: «Обычно мы вступали в разговор на повышенных тонах. Он бросал мне в лицо четвёртую заповедь “Чти отца своего!”, а я шипела на него, мол, родитель должен быть сперва почитаем, и уже затем го́спода из себя строить, и прочую чепуху в этом роде. Подобно чемпионам помойного ринга, мы выстоим вплоть до последнего раунда, поливаясь грязью: 
он назовёт меня тупой прошмандовкой (“fuckin' cunt”), а я его в ответ - остолопом конченным (“ignorant bollix”). Мы были отличной парой, не дававшей друг другу поблажек - иначе мы и не могли, ведь только такой представлялась нам жизнь и смерть» [5. Р. 128]. Подобная модель общения научила Милли искать компромисс в условиях нехватки любви и домашнего уюта.

Характер воспоминаний Милли кардинально меняется с наступлением второго акта: её точка зрения обособляется от материнской, акцентуация личности усиливается, эмоциональная экспрессия уступает место объективной модальности изложения. Из девочки, рассказы которой полны детских упрёков и сожалений, она превращается в женщину, которая познала жизнь в опыте предыдущих поколений. Этот путь Милли проделала, усвоив разочарования матери, которая стала для неё чем-то вроде путеводной звезды, и мечты прабабки, передавшей авантюрный настрой своих рассказов. В тех случаях, когда у нарратора нет сведений о событиях семейной хроники, связанных со смертью матери, то сюжетные лакуны заполняются сказаниями.

Милли поясняет сказаниями этимологию дома на Совином озере, которое является переименованным гэльским loch cailleach oiche (лох ка́йах охэ), или Водоёмом Тёмной ведьмы. Легенда о нем, стилизованная драматургом под ирландскую сагу, используется для отражения древнего, архетипического прошлого. Легенда представляет собой синтез греко-ирландских мифов, в котором формально фигурируют имена кельтских божеств, Бло и Куилте, но содержание во многом перекликается с древнегреческим мифом о Персефоне. Преданием о любви дочери горного божества Куилте к владыке цветов Бло Милли подчеркивает кульминацию отношений Мэй и Роберта. В контексте основной линии пьесы Мэй фигурирует как Куилте (ирл. coillte - «лес»), утопающая в озере собственных слез, а Роберт, её Бло (ирл. bláth - «цветок») - беспечный музыкант, под действием колдовских чар оставляющий любимую.

Отличие сказания Милли от античного мифа, в котором достигается компромисс (Персефона один раз в году возвращается к матери на Землю), заключается в отсутствии проблеска надежды. Смерть Куилте препятствует воссоединению любовников, а с наступлением весны Бло приходит к озеру, чтобы тосковать о потерянной любви, играя в уединении на свирели. Тёмная ведьма, зимой похищающая юношу в своё логово и сталкивающая девушку в озеро, появившееся из пролитых ею слёз, предстает в пьесе не любовницей Роберта, стремящейся разрушить супружеский брак, но, скоpee, духом, охраняющим легенду Совиного озера от места памяти - дома, который не должен там стоять. Нарратор расценивает очарование местом старины как ложное чувство: «Дрожь пробегает по телу, когда вспоминаешь легенду Совиного озера» [5. Р. 125].

Образ дома также несет в себе коннотации опасности. Защищаясь от зависти и непонимания сестёр, героиня признаётся, что её дом «был построен, чтобы сдерживать неврозы и прогонять кошмары» [5. Р. 158] вопреки убеждению персонажей в благополучии и жизнестойкости Мэй. Её ненависть к семейному гнезду, которое она создала, разлита в атмосфере, ставшей «тёмной, бесформенной, странно-манящей» [5. Р. 158]. В одном из диалогов Роберт утешает жену: «Сны о смерти всегда значат что-то другое; это эфирная и загадочная материя. Мне виделось много раз, как ты умираешь, и вот передо мной ты, живая, словно озёрная форель» [5. Р. 125]. Неслучайным является сравнение Мэй с рыбой, ареал обитания которой подводный, исключающий выход за его пределы.

Карр отмечает, что в своей пьесе она отыскивала «иную отправную точку, чтобы создать классическую трагедию в противоположность абсурдистскому взгляду на греческую идею судьбы, рока и миниатюрный побег (“little escape”)» [6]. Проецирование мифа, его циклической природы на реальность, передается особенностью сказаний, которыми Милли объясняет существование дома на Совином озере как диншенхас, как ментального образа, спродуцированного сознанием Мэй. Однако несмотря на смерть героини, пьеса завершается оптимистической нотой: дом, который стал гибельным для матери Милли, ознаменовал собой рождение повествования, логоса для нарратора.

Ирландская драматургия продолжает оставаться глубоко своеобразной и мало исследованной разновидностью западноевропейской драматургии. Свидетельством этого является, в частности, приём диншенхас, который позволяет воплотить в ирландских пьесах как мифологическое содержание, так и национальный колорит.

\section{СПИСОК ЛИТЕРАТУРЫ}

1. Бахтин М. М. Собр. соч. в 7 тт. М.: Языки славянских культур, 2012. Т. 3, С. 218-343.

2. Сартр Ж.-П. Воображаемое. Феноменологическая психология восприятия. СПб.: Наука, 2001. 319 с.

3. Фрил Б. Нужен перевод. Пьесы. СПб.: Балтийские сезоны, 2008. 464 с. 
4. Шкунаев С.В. Предания и мифы средневековой Ирландии. М.: Изд-во Моск. ун-та, 1991. 284 с.

5. Carr M. Plays One: "Low in the Dark", "The Mai", "Portia Coughlan", "By the Bod of Cats...". London: Faber and Faber, 1999. 341 p.

6. Clarity James F. A Playwright's Post-Beckett Period // The New York Times. 1994. URL: https://www.nytimes.com/ 1994/11/03/theater/a-playwright-s-post-beckett-period.html (дата обращения: 1.02.2019)

7. Dhomhnaill N. Dinnsheanchas: The Naming of High or Holy Places // The Geography of Identity / ed. by Patricia Yaeger. Michigan Press, 1996. P. 408-432.

8. Fuchs E. The Death of Character Perspectives on Theater after Modernism. Indiana Press, 1996. 225 p.

9. Heaney S. The Sense of Place // Preoccupations: Selected Prose 1968-1978. NY: Farrar, Straus and Giroux, 1980. P. 131-149.

10. Langridge N., Stephenson H. Marina Carr / Rage and Reason. Women Playwrights on Playwriting. Bloomsbury: Methuen Drama, 1997. P. 146-155.

11. Roche A. Contemporary Irish Drama [2nd edition]. Basingstoke: Palgrave Macmillan, 2009. 292 p.

Поступила в редакцию 18.04.2019

Якунин Александр Сергеевич, аспирант кафедры зарубежной филологии

ГАОУ ВО «Московский городской педагогический университет»

129226, Россия, г. Москва, 2-й Сельскохозяйственный проезд, 4

E-mail: ashga93@gmail.com

\section{A.S. Yakunin \\ STYLIZATION METHOD OF DINNSHEANCHAS IN THE PLAY “THE MAI" OF MARINA CARR}

DOI: $10.35634 / 2412-9534-2019-29-3-524-528$

The article discusses the method of dinnsheanchas and its stylization, which is characteristic of modern Irish dramaturgy, by means of which the playwright transforms objects of artistic space and endows characters with mental images. The embodiment of dinnsheanchas in the play "The Mai" is analyzed, and its role in uncovering the mythological potential in the works of Marina Carr is assessed.

Keywords: Irish drama, dinnsheanchas, stylization, mental image, artistic space.

\section{REFERENCES}

1. Bahtin M.M. Sobr. soch. v 7tt [Collected cit. in 7 vol.]. M.: Yazyki slavyanskih kul'tur, 2012. T. 3. S. 218-343. (In Russian)

2. Sartr Zh.-P. Voobrazhaemoe. Fenomenologicheskaya psihologiya vospriyatiya [The Imaginary. A Phenomenological Psychology of the Imagination]. SPb.: Nauka, 2001. 319 s. (In Russian)

3. Fril B. Nuzhen perevod. P'esy [Translations. Plays]. SPb.: Baltijskie sezony, 2008. 464 s. (In Russian)

4. Shkunaev S.V. Predaniya i mify srednevekovoj Irlandii [Legends and Myths of Medieval Ireland]. M.: Izd-vo Mosk. un-ta, 1991. 284 s. (In Russian)

5. Carr M. Plays One: "Low in the Dark", "The Mai", "Portia Coughlan", "By the Bod of Cats..." London: Faber and Faber, 1999. 341 p. (In English)

6. Clarity James F. A Playwright's Post-Beckett Period // The New York Times. 1994. URL: https://www.nytimes.com/ 1994/11/03/theater/a-playwright-s-post-beckett-period.html (In English)

7. Dhomhnaill N. Dinnsheanchas: The Naming of High or Holy Places // The Geography of Identity / ed. by Patricia Yaeger. Michigan Press, 1996. P. 408-432. 496 p. (In English)

8. Fuchs E. The Death of Character Perspectives on Theater after Modernism. Indiana Press, 1996. 225 p. (In English)

9. Heaney S. The Sense of Place // Preoccupations: Selected Prose 1968-1978. NY.: Farrar, Straus and Giroux, 1980. P. 131-149. 224 p. (In English)

10. Langridge N., Stephenson H. Marina Carr / Rage and Reason. Women Playwrights on Playwriting. Bloomsbury: Methuen Drama, 1997. P. 146-155. (In English)

11. Roche A. Contemporary Irish Drama [2nd edition]. Basingstoke: Palgrave Macmillan, 2009. 292 p. (In English)

Received 18.04.2019

Yakunin A.S., postgraduate student at Department of Foreign Philology

Moscow City University

Vtoroy Selskohoziajstvenny proezd, 4, Moscow, Russia, 129226

E-mail: ashga93@gmail.com 